\title{
EXPLORATIVE STUDY OF THE IMPACT OF DISTANCE LEARNING IN THE COVID-19 PANDEMIC ON ELEMENTARY SCHOOL
}

\author{
Vadlina Putry Prikustini ${ }^{1}$, Nabilah Dwi Safitri ${ }^{2}$, Ina Magdalena ${ }^{3}$ \\ ${ }^{1,2,3}$ Pendidikan Guru Sekolah Dasar, Universitas Muhammadiyah Tangerang, Indonesia
}

\begin{abstract}
Article Info
Article history:

Received: 04-02-2021

Revised: 28-07-2021

Published: 30-09-2021

Keywords:

Teaching and learning process COVID-19 pandemic Explorative Studies Online Learning

ABSTRACT

Since the COVID-19 outbreak, which requires all Indonesian citizens and even around the world to apply WFH (Work from Home) including all school residents in Indonesia who apply online or online-based learning at SDIT AR-RISAALAH. The implementation of online learning has consequences for a teacher to increase his role and competence, because competent teachers will be better able to manage classes and carry out evaluations for students both individually and in class. This study aims to determine the impact of online learning experienced by teachers and students during the COVID-19 pandemic. This research uses case study research, where in collecting data information with interview techniques, namely to find data on relevant matters. The results showed that the learning process during the pandemic changed by using a remote network. This has an impact on teachers because they are less than optimal in providing learning materials and disrupting the learning process which causes the expected learning objectives to not be achieved. So that it makes the material incomplete and the use of learning media in online learning is not optimal. Student assessment is also constrained by mere cognitive assessment. This research uses the case study method as the research method, by conducting interviews with 3 teachers and 3 students of SDIT AR-RISAALAH. Interviews were conducted in person/offline by approaching the informants.
\end{abstract}

This is an open access article under the CC BY-SA license.

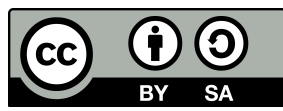

\section{Corresponding Author:}

Vadlina Putry Prikustini,

Pendidikan Guru Sekolah Dasar, Universitas Muhammadiyah Tangerang,

Jl. Perintis Kemerdekaan I/33 Babakan, Tangerang, Indonesia

Email: vadlinaputry120@gmail.com

\section{INTRODUCTION}

Education is a process of changing attitudes and behavior of a person or group of people in an effort to mature humans through teaching and training efforts. Education is usually called teaching, because education in general requires teaching and everyone is obliged to educate. In the learning process activities in schools to deliver material to students, teachers play an important role in guiding and teaching students. Learning is currently very inefficient and cannot meet face-to-face between teachers, students and friends, because of COVID-19 (Corona Virus Disease). Therefore, during the COVID-19 pandemic, students were asked to study at home using online social media. Based on research conducted through observational interviews that online learning is learning without face to face directly between teachers and students by accessing the internet network and using social media to exchange information and use the WhatsApp application. 
Ease of online learning, among others, for teachers, student learning outcomes can be known directly, learning activities are not limited to distance, time and place, in the learning process can be accompanied by parents, students can access the internet network, students can take advantage of existing media in the surrounding environment, have lots of time with family. While the obstacles experienced by teachers and students include, teachers in evaluating learning activities must be more focused and thorough, students or their parents do not have Android-based mobile phones, students or parents do not have internet data packages, it is difficult to understand the material delivered by the teacher through the media. online, the lack of understanding of parents so that they cannot teach their children, the internet network is not stable.

The current outbreak of the COVID-19 pandemic, globally has driven many sectors of people's lives and experienced many changes, including in the world of education. In Indonesia, schools and universities have eliminated face-to-face meetings or face-to-face meetings. As an alternative, the Indonesian government encourages all learning activities to be carried out remotely. On the other hand, the implementation of distance learning experiences obstacles such as the lack of skills of teachers or teaching staff in managing the learning model, including in using various online learning instruments.

Online learning is learning that is carried out using the internet as a place to transmit knowledge. This form of learning can be done anytime and anywhere without being bound by time and without having to meet face to face. In the era of the development of online learning technology, it is increasingly sophisticated with various applications and features that make it easier for users. Not being bound by time and being done without meeting face to face are the advantages of online learning that educators usually use. As is currently the case, online learning is the only form of learning that educators can do when a natural disaster or global pandemic occurs. Indonesia applies social distance (social restrictions) in all aspects of life, including the world of education. Therefore, online learning can be said to be the only learning option that can be done by educators to improve the quality of learning in Indonesia.

Learning is an important instrument for the intellectual life of the nation. As an important system in education, learning is organized as a space for interaction to build teacher-student relationships to develop cognitive potential, run effectively and an internal learning atmosphere that makes students interested in learning. Learning can also be influenced by external factors, such as the COVID-19 outbreak. Reality shows that the dynamics of learning in Indonesia are currently disrupted by the COVID-19 outbreak which has an impact, including:

1. Schools are transferred to homes through an online learning process

2. There is a transformation of technology-based learning media through the use of WhatsApp Group, Zoom, Google Classroom, WebEx, Youtube, and TV channels (TVRI)

3. Adjustment of learning methods

4. Adjustment of learning evaluation to determine standard of grade promotion and graduation

5. The demand for collaboration between parents of students at home as a substitute for teachers to control children's learning.

The learning process that is currently running at SDIT AR-RISAALAH is using conventional learning models, but often teachers are also burdened with administrative tasks that are very time-consuming so that sometimes the learning process is not effective and is usually not carried out. This causes the learning outcomes of these subjects to be usually not achieved at the end of the lesson so that many students do not understand/understand the subject matter.

For this reason, partners need a solution to solve learning problems that cannot be solved in class and are not understood by students. So that with the e-learning system training with synchronous features, it can provide learning services that can be carried out anytime and anywhere, and can interact directly with the teacher so that students can ask questions directly when something is not understood about the material. Based on the results achieved, learning which was originally with conventional systems, can be combined with the zoom meeting application for face-to-face live streaming.

Online learning is learning that is done online, using learning applications. Online learning is a learning that is done without face-to-face, but using an available platform. All learning materials are distributed online and tests are also conducted online. This online learning system is assisted by several applications, such as Google Classroom, Google Meet. During the implementation of online learning, students have ample time to learn. Students can learn anytime and anywhere, without being limited by space and time.

This research is expected to provide benefits for various parties, including benefits for teachers, for students, for institutions and for researchers. The benefit of this research for teachers is to provide insight into 
knowledge about innovative learning models.

This is evidenced by the results of research from the Journal of education, psychology and counseling entitled "Explorative Study of the Impact of the COVID-19 Pandemic on Online Learning Processes in Elementary Schools" that the impact felt by students on the teaching and learning process at home is that students feel forced to study remotely without adequate facilities and infrastructure at home (Purwanto, Wijayanti, Hyun, \& Asbari, 2020). The benefits of this research for students are being able to foster student interest in learning when participating in learning, making it easier for students to capture learning material. The benefits of this research for institutions are as input and consideration to overcome problems when improving learning outcomes, students can improve and improve the quality of education in schools.

The benefit of research for researchers is to increase knowledge, especially about the evaluation of interesting and varied learning, varied learning in order to improve student learning outcomes so that later they can be implemented when they become teachers. The purpose of this study was to identify obtaining information about the obstacles to the online teaching and learning process at home as a result of the COVID19 pandemic. The research uses an exploratory case study method and the research approach uses a qualitative case study method that is used to obtain information on the constraints and consequences of the COVID-19 pandemic on teaching and learning activities in elementary schools. In this study, the respondents were 6 teachers and students in a school. base in Jakarta. For confidentiality purposes, respondents were given the initials G1, G2, G3, A, S and Q. Semi-structured interviews were conducted and a list of questions compiled for the interviews was developed based on the relevant literature. The respondents for this study were teachers and students at an elementary school in Jakarta.

The results of this study are that there are several obstacles experienced by students, teachers and parents in online teaching and learning activities, namely lack of mastery of technology, additional internet quota costs, additional work for parents in accompanying children to learn, communication and socialization between students, teachers and parents are reduced and working hours become unlimited for teachers because they have to communicate and coordinate with parents, other teachers, and school principals.

\section{RESEARCH METHOD}

This study uses a case study. A case study is an in-depth exploration of a bound system based on extensive data collection. A case study involves the investigation of a case, which can be defined as an entity or object of study that is restricted, or separated from, research in terms of time, place, or physical boundaries. It is important to understand that cases can be individuals, programs, activities, schools, classrooms, or groups. Once the cases are clearly defined, the researcher investigates them in depth, usually using several interviews, observations, field methods, and documentation. Data collection, such as Collective case studies: involves several cases, can occur over many sites, using multiple individuals.

The conceptual framework for a case study is that by gathering in-depth information about a case, the researcher will reach an in-depth understanding of the case, whether the case is an individual, a group, a class, or a school. At the planning stage, researchers conducted direct interviews to the research location by conducting questions and answers to 3 teachers and 3 students at SDIT AR-RISAALAH West Jakarta. The researcher asked about the obstacles experienced during this distance learning teaching. From the results of this study, the aim was to determine the impact during online learning on the increase in student learning outcomes at SDIT AR-RISAALAH. The research method used in this study is a case study research method using data collection techniques, namely interview techniques. The author uses an interview technique by collecting information from teachers at SDIT AR-RISAALAH.

In this study, the subjects studied were 3 teachers and 3 students at SDIT AR-RISAALAH. The data collection technique used is interview. This interview technique is used to collect data regarding the implementation of learning by direct question and answer by the teacher concerned. While the notes from the interviews were to record things that happened during teaching and learning activities. Based on the results of interviews, it can be seen the obstacles or problems that arise during learning activities. The research method is a case study. Data were collected through sentences and answers from the research subjects through direct interviews. The research subject is SDIT-AR-RISAALAH teachers. The researcher is the key or main in this research and is supported by the interview instrument. The answer from the interview is a description of the question about the impact of online learning during the COVID-19 pandemic. Research Subjects Questionnaire for educators:

1. How is the implementation of online learning in the era of the COVID-19 pandemic? 
2. What are the applications used in online learning in the era of the COVID-19 pandemic?

3. What is the effectiveness and impact of online learning in the era of the COVID-19 pandemic?

The goal is to understand the impact of distance learning. Educators and students are expected to have technical skills in operating various online learning applications. In addition, teachers and students also understand how to apply these distance learning tools appropriately in order to achieve optimal learning objectives.

\section{RESULT AND DISCUSSION}

\subsection{Result}

The results of the study show that the impact of online learning in the midst of the COVID-19 pandemic is that by using an online learning system they are not yet proficient. Determination of the subject of this study using snowball sampling. The subjects of this study consisted of 3 students and 3 elementary school teachers in the use of technology. Based on Q's opinion, he likes online learning because his time is short. This learning activity went quite well because it used a video application or by telephone. The following are the results of an interview with Q:

Q : What media are you currently using during the COVID-19 period?

Q : The learning is using cellphones and WhatsApp

$\mathrm{Q}$ : Are you happy with online learning?

$\mathrm{Q}$ : Tired of not being able to meet friends, and difficulty in learning because it is less effective, one of which is signal problems

The following is an excerpt from the interview with A:

Q : What media are you currently using during the COVID-19 period?

A : Learning to use HP and WhatsApp

Q : Are you happy with online learning?

A : Happy, but sometimes there are quota constraints

The following is an excerpt from the interview with S:

Q : What media are you currently using during the COVID-19 period?

$\mathrm{S}$ : Learning through online using google forms, zoom application

$\mathrm{Q}$ : Are you happy with online learning?

S : I'm very happy, but I like fighting over cellphones with my sister, because they don't have their own cellphones.

The following is an interview with a teacher about the impact of online learning on students in the COVID-19 pandemic era:

Q : How is the implementation of online learning in the era of the COVID-19 pandemic?

G1 : Keep going, continue the previous learning through online

Q : What are the applications used in online learning in the era of the COVID-19 pandemic?

G1 : Via Zoom and WhatsApp Group

$\mathrm{Q}$ : How effective is online learning in the COVID-19 pandemic era?

G1 : The learning has been effective but the signal and internet quota are hampered

The following is an interview with a teacher about the impact of online learning on students in the COVID-19 pandemic era:

Q : How is the implementation of online learning in the era of the COVID-19 pandemic?

G2 : Still running and still being monitored by the school 
Q : What are the applications used in online learning in the era of the COVID-19 pandemic?

G2 : Via WhatsApp and zoom app

Q : How effective is online learning in the COVID-19 pandemic era?

G2 : The learning has been effective but it is hampered by the coordination of parents in assisting students in learning due to the busyness of parents at work. The reach of the internet experienced by students makes the learning process disrupted so that students are not optimal in receiving the material presented by the educator.

The following is an interview with a teacher about the impact of online learning on students in the COVID-19 pandemic era:

Q : How is the implementation of online learning in the era of the COVID-19 pandemic?

G3 : Still running and still being monitored by the school

$\mathrm{Q}$ : What are the applications used in online learning in the era of the COVID-19 pandemic?

G3 : Via WhatsApp group and zoom app

Q : How effective is online learning in the COVID-19 pandemic era?

G3 : The learning has been effective but it is hampered by the coordination of parents in assisting students in learning due to the busyness of parents at work, parents do not have the cost to purchase internet quota.

The researcher conducted interviews with 3 students and 3 elementary school teachers of SDIT ARRISAALAH. This is done to get clearer information about the success of distance learning during the learning process, as well as suggestions for the next learning process to be better and achieve the maximum level of success. Before carrying out an activity, it should begin with planning, so that the activity can run more smoothly.

\subsection{Discussion}

The impact that students feel on the teaching and learning process at home is that students feel compelled to study remotely without adequate facilities and infrastructure at home. This facility is very important for carrying out the teaching and learning process, for online learning at home provided in facilities such as laptops, or mobile phones that will make it easier for students to listen to the online teaching and learning process. The next obstacle is that students do not have a culture of distance learning because so far the learning system is through face-to-face, students are accustomed to being at school to interact with their friends, play and joke with their friends and meet face-to-face with their teachers, with the existence of learning methods. Distance learning makes students need time to adapt and deal with new changes that will indirectly affect their learning ability. The next impact experienced by students is that schools are closed for too long making children bored, children are getting bored at home and immediately go to school with their friends, students are accustomed to being at school to interact with their friends, play and joke with friends. his friends and face to face with his teachers. Then students will lose their social spirit, if at school they can play and interact with their friends but this time they can't and are alone at home with their parents, interaction with fellow friends, teachers and people at school will decrease.

The COVID-19 outbreak forces students to use technology, so like it or not and like it or not, they have to learn and be ready to teach remotely using technology. Each school provides distance learning tools and systems and provides technical guidance to teachers so that they can use modern technology in learning to improve the quality of students in primary schools. According to Zapalska (2006) if a particular student learns best in a certain way, he or she must be exposed to a variety of learning experiences to become a more flexible online learner. According to Drago (2004), the findings show that online students are more likely to have stronger visual and literacy learning styles. Furthermore, reading-writing students and students with strong in all four learning styles to maintain effectiveness were lower than other students while aural/read-write students and students who were not strong in any learning style tended to like learning more highly than other students.

According to Watjatrakul (2016), neuroticism and experience of experiences that affect students' intention to adopt online learning through the five perceived values of online learning. In particular, students who are open to experience pay more attention to the quality of online learning. Students who are more neurotic avoid the stress of studying in unfamiliar situations. In addition, students tend to adopt online learning when 
they feel that online learning fulfills their emotional and social needs. Discuss more about things and meeting for theory and practice provided.

Butler (2012) stated that student learning needs and online learning environments are similar and congruent. Offerings at local high schools are limited, resulting in boredom and lack of challenge. Students want courses that are new and exciting and online learning fulfills that need. Students work at their own pace and ability and enjoy the challenge, freedom, and independence that result from online learning. Students who often skip school are easy to accommodate. Obstacles faced by parents are the additional cost of buying internet quotas, online technology requires a network connection to the internet, tv, and quotas because the level of internet quota usage will increase and will increase the burden on parents' expenses. To do online learning for several months, of course, more quota will be needed and will automatically increase the cost of buying internet quota. The next obstacle that parents feel is that they have to spend more time for children who accompany online learning, they have to divide more time to assist children in online learning, to assist children in online learning will certainly affect work activities the day-to-day routines will decrease, sometimes the parents also learn with the children and help do the assignments with the children.

Online learning also forces parents to use technology, so like it or not and like it or not, they have to learn and be ready to teach remotely using technology. Parents must provide distance learning tools and systems and guidance to their children so that they can use modern technology in learning to improve the quality of their children. Some parents who have problems finding and demanding to accompany their children's learning at home take it to the teacher. However, there are also many parents who are very appreciative because they have experienced for themselves that teaching two children at home is difficult, especially like a teacher who has to teach 20 children in a class.

Yoo (2014) feels that there is a difference between ideal and reality in integrating interactions as part of online activities in learning. The impact on teachers, the impact felt by teachers is that not all are proficient in using internet technology or social media as a means of learning, some senior teachers have not been fully able to use devices or facilities to support online learning activities and need assistance and training first. And the competence of teachers in using technology will affect the quality of teaching and learning programs, therefore, before an online learning program is held, teachers must be given training first.

Some of the impacts felt by teachers are on the online teaching and learning process at home without adequate facilities and infrastructure at home. This facility is very important for the learning process, for online learning at home provided in facilities such as laptops, computers or mobile phones that will make it easier for teachers to provide online teaching and learning materials. The next obstacle is that teachers do not have a culture of distance learning because so far the learning system is through face-to-face, teachers are accustomed to being in school to interact with students, with the distance learning method, teachers need time to adapt and they face challenges. new changes that will indirectly affect the quality of learning outcomes. The obstacles faced by parents are the additional cost of buying internet quotas, online technology requires a network connection to the internet, $\mathrm{tv}$, and quotas, therefore the level of internet quota usage will increase and will increase the burden on parents' expenses. To do online learning for several months, of course, more quota will be needed and will automatically increase the cost of buying internet quota. The next obstacle that parents feel is that they have to spend more time with their children accompanying online learning, they have to divide more time to assist their children in online learning, to assist children in online learning will certainly affect their daily routine work activities. -the days will be reduced, sometimes the parents also learn with their children and help do the tasks with their children.

Online learning also forces parents to use technology, so like it or not and like it or not, they have to learn and be ready to teach remotely using technology. Parents must prepare distance learning tools and systems and provide guidance to children so that they can use modern technology in learning to improve the quality of their children. Parents who have problems with their work demands and demands to accompany their children's learning at home take it out on the teacher. However, there are also many parents who are very appreciative because they have experienced for themselves that teaching two children at home is difficult, especially like a teacher who has to teach 20 children in a class. Yoo (2014) feels that there is a gap between ideal and reality in integrating interactions as part of online activities in learning. The impact on teachers, the impact felt by teachers is that not all are proficient in using internet technology or social media as a means of learning, some senior teachers have not been fully able to use devices or facilities to support online learning activities and need assistance and training first. And the competence of teachers in using technology will affect the quality of teaching and learning programs, therefore, before an online learning program is held, teachers 
are required to be given training first.

Some of the impacts felt by teachers are on the online teaching and learning process at home without adequate facilities and infrastructure at home. This facility is very important for the smooth teaching and learning process, for online learning at home, facilities such as laptops, computers or mobile phones should be provided which will make it easier for teachers to provide online teaching and learning materials. The next obstacle is that there is no culture of distance learning for teachers because so far the learning system has been implemented face-to-face, teachers are used to being in school to interact with students, with the distance learning method, teachers need time to adapt and they face new changes that will indirectly affect the quality of learning outcomes.

That is, schools are closed for too long making teachers bored, teachers are used to being at school to interact with their friends. Then teachers will also lose their social spirit, if at school they can play and interact with other teachers and students but this time they are not used to being at home alone.

The COVID-19 outbreak has forced teachers to use technology, so like it or not and like it or not, they have to learn and be ready to teach remotely using technology. Each school provides distance learning tools and systems and provides technical guidance to teachers so that they can use modern technology in learning to improve the quality of students in primary schools. The obstacles faced by teachers are the increase in the cost of purchasing internet quotas, online technology requires a network connection to the internet and quotas because the level of use of internet quotas will increase and will increase the burden of teacher spending. To do online learning for several months, of course, more quota will be needed and will automatically increase the cost of buying internet quota. Teacher competence in utilizing technology and mastering technology for learning to increase rapidly to respond to online Home Learning. Communication between teachers and schools with parents must be established smoothly. This means that there are additional costs that must be paid by the teacher, both in the form of material and non-material. For example telephone credit, credit for internet access, and especially time.

One of the costs that must be automatically paid by the teacher is that the teacher must also provide technical support to parents in the event of interference, both related to technology that is directly used in the learning process as well as setting up devices used by students. Unlimited working hours because they have to communicate and interact with students, parents, other teachers, and school principals. Not every teacher quickly adopts and learns technology, so as a coordinator my working hours are not limited to working days. Saturday and Sunday night, it is still morally and responsibly to prepare teachers who still need support to carry out learning at home. According to Zhao (2003), the current literature review found that there is a lot of research on the implementation of technology in online education related to cost and efficiency, that improving the quality and effectiveness of online education requires a framework that must be implemented in schools. a framework that proposes practical guidance for stakeholders in the quality of online teaching and learning. According to Chakraborty (2014) revealed several factors that can create an interesting learning experience for online learners. The main factors are as follows: creating and maintaining a positive learning environment; building a learning community; provide timely consistent feedback; and use the right technology to deliver the right content. According to Lewis (2015) increasing online learning opportunities in today's society, librarians need to consider additional ways to design online instruction effectively. The strategies needed to teach and learn online successfully require an understanding of learning styles and how they can best be handled in an online environment. As is the case in face-to-face classes, certain teaching styles or face-to-face styles must be extended to address different learning styles when teaching online.

\section{CONCLUSION}

The impact that students feel on the teaching and learning process at home is that students feel forced to study remotely without adequate facilities and infrastructure at home. This facility is very important for the smooth teaching and learning process, for online learning at home, facilities such as laptops, computers or mobile phones should be provided which will make it easier for students to listen to the online teaching and learning process. The impact on parents is that the obstacles faced by parents are the increase in the cost of purchasing internet quotas, online technology requires a network connection to the internet, tv, and quotas, therefore the level of use of internet quotas will increase and will increase the burden on parents' expenses. To do online learning for several months, of course, more quota will be needed and it will automatically increase the cost of buying internet quota. The impact on teachers is the impact felt by teachers, namely not all are 
proficient in using internet technology or social media as a learning tool, some senior teachers have not been fully able to use devices or facilities to support online learning activities and need assistance and training first. And the competence of teachers in using technology will affect the quality of teaching and learning programs, therefore, before an online learning program is held, teachers are required to be given training first. How much impact does the teacher have on the online teaching and learning process at home without adequate facilities and infrastructure at home. This facility is very important for the smooth teaching and learning process, for online learning at home, facilities such as laptops, computers or cellphones should first be provided which will make it easier for teachers to provide teaching and learning materials.

Suggestions and inputs to relevant agencies, namely before the online learning program is implemented, it is necessary to prepare supporting facilities, competencies and training for students, teachers and parents. Without good preparation it will affect the quality of teaching and learning outcomes. For children aged 1-3 still need parental help to accompany learning at home, at least to prepare technology before and after online learning takes place so that students can take part in online learning. Thus the support and cooperation of parents for the success of learning is needed. Communication between teachers and schools with parents must be established smoothly. This means that there are additional costs that must be paid by the teacher, both in the form of material and non-material. For example telephone credit, credit for internet access, and especially time. One of the costs that automatically must be paid by the teacher is that the teacher must also provide technical support to parents in the event of glitches (problems) properly related to technology that is directly used in the learning process and device settings used by students. Unlimited working hours because they have to communicate and coordinate with students, parents, other teachers, and school principals. Not every teacher quickly adopts and learns technology, so as a coordinator my working hours are not limited on weekdays. Saturday and Sunday night are still required morally and responsibly to prepare teachers who still need support to run home learning.

\section{REFERENCES}

Butler Kaler, C. (2012). A model of successful adaptation to online learning for college-bound Native American high school students. Multicultural Education \& Technology Journal, 6(2), 60-76. doi:10.1108/ 17504971211236245

Chakraborty, M., \& Muyia Nafukho, F. (2014). Strengthening student engagement: what do students want in online courses? European Journal of Training and Development, 38(9), 782-802. doi:10.1108/EJTD11-2013-0123

Drago, W. A., \& Wagner, R. J. (2004). Vark preferred learning styles and online education. Management Research News, 27(7), 1-13. doi:10.1108/01409170410784211

Lewis, S., Whiteside, A., \& Dikkers, A. (2015). Providing Chances for Students to Recover Credit: Is Online Learning a Solution? Exploring Pedagogies for Diverse Learners. Advances in Research on Teaching, 25(11), 143-157. doi:10.1108/S1479-36872015000002700

Purwanto, A., Wijayanti, L. M., Hyun, C. C., \& Asbari, M. (2020). THE EFFECT OF TANSFORMATIONAL, TRANSACTIONAL, AUTHENTIC AND AUTHORITARIAN LEADERSHIP STYLE TOWARD LECTURE PERFORMANCE OF PRIVATE UNIVERSITY IN TANGERANG. Dinasti International Journal of Digital Business Management, 1(1), 29-42. doi:10.31933/dijdbm.v1i1.88

Watjatrakul, B. (2016). Online learning adoption: effects of neuroticism, openness to experience, and perceived values. Interactive Technology and Smart Education, 13(3), 229-243. doi:10.1108/ITSE-06-2016-0017

Yoo, S., Jeong Kim, H., \& Young Kwon, S. (2014). Between ideal and reality. Journal for Multicultural Education, 8(1), 13-30. doi:10.1108/JME-04-2013-0018

Zapalska, A., \& Brozik, D. (2006). Learning styles and online education. Campus-Wide Information Systems, 23(5), 325-335. doi:10.1108/10650740610714080

Zhao, F. (2003). Enhancing the quality of online higher education through measurement. Quality Assurance in Education, 11(4), 214-221. doi:10.1108/09684880310501395 